\title{
A obviação em complementação sentencial no português brasileiro e sua relação com predicados não epistêmicos
}

\author{
Obviation in Sentential Complementation in Brazilian \\ Portuguese and its Relation to Non-epistemic Predicates
}

Vivian Meira

Universidade do Estado da Bahia, Brumado, Bahia / Brasil FAPESB

vivianmeira@gmail.com

Resumo: Este artigo investiga padrões de referencialidade em complementação sentencial no português, italiano e grego moderno, especialmente o fenômeno conhecido como obviação ou referência disjunta. Trata-se de uma restrição atestada nas línguas e se caracteriza pelo fato de o sujeito da oração subordinada ser obrigatoriamente disjunto em referência ao sujeito da oração matriz. Tradicionalmente, assume-se que a obviação é uma propriedade de complementação subjuntiva ou um fenômeno resultante, juntamente com o controle, da competição entre formas finitas / não finitas. No entanto, os dados das línguas analisadas não condizem com essas hipóteses. Assumindo a teoria de seleção semântica e a versão minimalista de subcategorização (cf. ADGER, 2004), propõe-se que a obviação, exibida em complementação sentencial, é uma restrição semântica exigida por três tipos de predicados: os causativos, os volitivos e os perceptivos físicos, que serão tomados como predicados capazes de impor restrições semânticas aos seus complementos.

Palavras-chave: referência disjunta; predicado matriz; interface sintaxesemântica; línguas românicas/línguas da área balcânica. 
Abstract: This paper investigates patterns of referentiality in sentential complementation in Portuguese, Italian and Modern Greek, especially the phenomenon known as obviation or disjoint reference. This is a constraint attested in languages, and it is characterized by the fact that the subject of the subordinate clause must be disjoint in reference to the subject of the matrix sentence. Traditionally, obviation has been assumed to be a property of subjunctive complementation, or a phenomenon arising along with the control from the competition between finite/non-finite forms. However, the data are not consistent with these hypotheses. Based on the theory of semantic selection and a minimalist version of subcategorization (cf. ADGER, 2004), this thesis proposes that obviation, in sentential complementation, is a semantic constraint required by three types of predicates, the causative, volitional and physical perceptive predicates, which will be taken as predicates able to impose semantic constraints on their complements.

Keywords: disjoint reference; main predicate; syntax-semantics interface; Romance and Balkan languages.

Recebido em 28 de novembro de 2017.

Aceito em 19 de dezembro de 2017.

\section{Introdução}

Uma propriedade semântica das línguas é possibilitar que elementos mantenham relações de referencialidade uns com os outros em diferentes posições nas sentenças. Por exemplo, em (1), himself, ocupando a posição de objeto, faz referência ao sujeito John. Em (2), o objeto him não pode ser correferente ao sujeito John e, em (3), a categoria vazia, na posição de sujeito do complemento encaixado, pode fazer referência ao sujeito matriz, Giovanni, ou a outro elemento que não está na sentença.

(1) John ${ }_{1}$ loves himself $f_{1 / 2}$. (Inglês)

'João se ama'

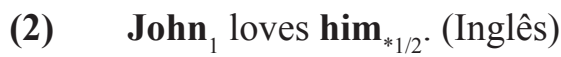

'João o ama.' 
(3) Giovanni ha detto che $\mathbf{c v}_{1 / 2}{ }^{1}$ comprerà una nuova casa. (Italiano)

'João disse que comprará uma nova casa.'

Essas relações semânticas de referencialidade nas línguas podem ser de três tipos: correferência, como em (1), não correferência, como em (2), e referência livre, como em (3). Tendo como base a Teoria de Princípios e Parâmetros (cf. Chomsky, 1981), quadro teórico no qual nos basearemos nesta investigação, essa propriedade semântica de referencialidade pode ser capturada por meio da Teoria da Ligação, que trata das condições/exigências de ligação de três tipos de sintagmas nominais: as anáforas, os pronomes e as expressões referenciais, bem como por meio da Teoria do Controle, que diz respeito às relações sintáticas e interpretativas entre uma categoria vazia (PRO) e seu antecedente em configurações não finitas.

Nos contextos de complementação sentencial, essas relações interpretativas podem ser exibidas entre os DPs sujeitos da sentença matriz e encaixada, como nas sentenças em (4), e entre o objeto da oração matriz e o sujeito da oração complemento, ilustrado em (5).

(4) a. João quer viajar.

b. João quer que ele viaje.

c. João pensa que ele vai viajar.

(5) João lamentou a Maria eles irem embora.

Nesta pesquisa, desenvolveremos uma investigação sobre as relações de referencialidade entre sujeitos sintáticos nos contextos de complementação sentencial, especificamente nos tipos de construções delineados em (4). Os contextos apresentados em (1), (2) e (5) não serão alvo de nossa análise, já que (1) e (2) não representam contextos de complementação sentencial e (5) trata de relação de referencialidade entre objeto e sujeito de complemento, não se assemelhando ao contexto em (3) e (4).

\footnotetext{
${ }^{1}$ Nos exemplos, a sigla cv abrevia categoria vazia, referindo-se ao sujeito nulo em questão.
} 
O padrão de referencialidade denotado em (4a) é tratado pela literatura como contexto de correferência ou controle. Em (4b), a ausência de correferência entre os sujeitos é denominada referência disjunta ou obviação e, em (4c), há possibilidade tanto de correferência quanto de não correferência entre os sujeitos, o que se convencionou chamar de referência livre.

Tomaremos dados do português do Brasil para análise e teceremos comentários sobre esse fenômeno no italiano e em línguas da área balcânica, como o grego moderno, que não exibe esse fenômeno no mesmo contexto exibido pelas línguas românicas. A nossa hipótese é a de que a referência disjunta obrigatória (RD) em complementação sentencial é uma restrição semântica imposta pelo tipo de predicado matriz, o que faz esse efeito semântico ser uma propriedade universal de línguas que dispõem desses contextos em complementação sentencial. Nas próximas seções, apresentaremos nosso objeto de estudo, a problemática que o envolve, algumas tentativas da literatura que tentam explicá-lo, bem como a análise e os resultados dos dados investigados.

\section{Tentativas na literatura para explicar controle e obviação nas línguas}

Há duas hipóteses muito debatidas na literatura que se propõem explicar os contextos nos quais controle e obviação são exibidos nas línguas. A primeira delas é a Hipótese da Rivalidade Subjuntivo / Infinitivo (HRSI), que toma finitude como uma noção importante para explicar padrão de referencialidade nas línguas. Segundo essa hipótese, apenas línguas que exibem sentenças finitas / não finitas podem desencadear obviação e controle, já que se assume que esses fenômenos são desencadeados pela competição entre estruturas finitas / não finitas (cf. BOUCHARD, 1984; FARKAS, 1992; KRAPOVA, 2001). Essas pesquisas se baseiam na ideia de que há marcação de Caso na estrutura finita e seu bloqueio na não finita, como está ilustrado no contraste entre (6a) e (6b) do português do Brasil (PB).

$$
\begin{aligned}
& \text { a. João } \mathrm{o}_{1} \text { quer } \mathrm{cv}_{1_{1 * 2}} \text { comprar a bola. } \\
& \text { b. João } \mathrm{o}_{1} \text { quer que ele }{ }_{*_{1 / 2}} \text { compre a bola. }
\end{aligned}
$$

Uma descrição superficial do contexto em (6a) nos permite dizer que é uma estrutura de infinitivo, na qual é desencadeada correferência 
pronominal e não há licenciamento de sujeito nominativo visível na complementação não finita da encaixada, o que desencadeia o chamado controle. Por outro lado, a sentença (6b) ilustra um contexto de oração finita, licenciando complementação subjuntiva com sujeito nominatvo disjunto referencialmente do sujeito matriz.

As abordagens que se baseiam nessa hipótese confirmam que o contraste obviação/controle é possível nas línguas românicas, já que estas exibem complementação finita/não finita, mas não é possível em línguas da área balcânica, como o grego moderno, já que estas não dispõem de infinitivos.

Como a obviação tem sido documentada nos contextos de volitivos, a outra linha de investigação tenta associar a obviação à modalidade subjuntiva, tomando-a como uma propriedade de modo subjuntivo (cf. BORER, 1989; KEMPCHINSKY, 1998). Nesse caso, toma-se como base a Teoria da Ligação (TL) e a noção de Domínio de Ligação (DL) para explicar a ausência de correferência pronominal nesses contextos. A relação de referencialidade entre um pronominal e seu antecedente nessa linha é capturada pelo Princípio B, que trata do comportamento dos pronomes e exige que estes sejam livres em seu Domínio.

No entanto, esse pressuposto não tem conseguido dar conta das construções com sujeitos pronominais obviativos, e o problema que resulta disso é tentar explicar por que as restrições de ligação sobre pronomes obviativos, como em (7), parecem ser mais rigorosas do que aquelas impostas sobre os pronomes em outras estruturas, como em (8). Observe o par de sentenças em (7) e (8).

a. João quer que ele $_{*_{1 / 2}}$ viaje.

b. *Eu quero que eu viaje.

(8) a. João ${ }_{1}$ acha que ele ${ }_{1 / 2}$ vai viajar.

b. Eu acho que eu vou viajar.

O pronome obviativo da encaixada nas sentenças em (7) obedece não apenas ao Princípio B da TL, como também deve ser livre em relação ao sujeito da oração matriz, comportando-se diferentemente dos pronomes nas sentenças em (8). Esta diferença no comportamento do pronome obviativo em relação a outros pronomes levou Bouchard (1984) a sugerir que a referência disjunta não fosse analisada a partir de pressupostos da TL. 
Outras abordagens, seguindo a linha de investigação da Teoria de Regência e Ligação - TRL, tentam explicar a diferença de comportamento entre as construções em (7) e (8), sugerindo que sentenças subjuntivas como em (7) se caracterizam por ter tempo dependente em relação à oração matriz. Essa anaforicidade temporal desencadeia uma extensão do Domínio de Ligação da encaixada, que se estende para a oração matriz e, portanto, o sujeito pronominal da encaixada tem de ser diferente referencialmente do sujeito matriz, já que estão no mesmo domínio, a fim de não violar o Principio B (cf. RAPOSO, 1985; BORER, 1989; KEMPCHINSKY, 1998).

Essas abordagens sugerem duas direções. Por um lado, a obviação tem sido tomada como uma propriedade de modo subjuntivo, especialmente dos contextos de predicados volitivos. E, em outra direção, muitos trabalhos desenvolvidos na década de 80 , seguindo orientações da TRL, tentam correlacionar o 'controle' à questão de não finitude sentencial, de modo que o locus por excelência de ocorrência desse fenômeno é o de construções não finitas. Argumenta-se que o DP matriz controla a interpretação da posição de sujeito vazio da oração infinitiva, desencadeando a correferência, como exemplificado em (9), em que João e PRO - sujeito do infinitivo - mantêm uma relação anafórica entre si.

(9) João quer PRO comprar um livro. ${ }^{2}$

No entanto, essas hipóteses podem ser contestadas com base em dados do português, italiano e grego moderno, o que será exposto na próxima seção.

\section{Contraevidências para a Hipótese da Rivalidade Subjuntivo/ Infinitivo e para a obviação subjuntiva}

Os dados do português brasileiro nos mostram que a obviação pode ser desencadeada em outros contextos, além da complementação subjuntiva, como nos contextos de complementação indicativa selecionada por predicados perceptivos físicos, como em (10a), nos contextos de infinitivo flexionado selecionados por predicados causativos e perceptivos

\footnotetext{
${ }^{2}$ Para uma análise semântica da sentença em (9), ver Chierchia (1989) https://scholar. harvard.edu/files/chierchia/files/1989_de-se.pdf
} 
no português, como em (10b), além dos contextos de volitivos e causativos com complementação subjuntiva, como em (10c). E controle não é exibido apenas em contextos não finitos, pois a relação 'anafórica' entre sujeitos pode ser observada em alguns casos de complementação indicativa, no PB, como em (11) (cf. FERREIRA, 2000).

(10) a. João viu que ele ${ }_{*_{1 / 2}}$ foi embora.

b. João e Maria ${ }_{1}$ mandaram/viram eles $_{*_{1 / 2}}$ irem embora.

c. João ${ }_{1}$ queria/mandou que ele ${ }_{* 1 / 2}$ fosse embora.

(11) João disse que $\mathrm{cv}_{1 /{ }^{2}}$ vai viajar hoje. (PB)

O grego moderno também fornece evidências contrárias à hipótese que tenta ligar a obviação à modalidade subjuntiva, pois os predicados volitivos, nessa língua, não exibem referência disjunta, mas referência livre, como em (12).

(12) Ta koritsia ${ }_{1}$ thelun na pane $_{1 / 2}$ sto sinema.

'As meninas ${ }_{1}$ querer-IND que-SBJV ir ao cinema.'

'As meninas querem que elas vão ao cinema.'

Para explicar esse dado, costuma-se assumir na literatura, tomando como base a HRSI, que o grego, por não exibir infinitivos, não desencadeia obviação, o que explicaria a referência livre nos volitivos em (12). No entanto, os fatos não corroboram essa hipótese, pois, nos contextos de predicados causativos e de perceptivos físicos, há obviação no grego, como ilustrado no par de sentenças em (13).

(13) a. OYanis ${ }_{1}$ parigile na $\mathrm{cv}_{*_{1 / 2}}$ plini ta piata piogrigora.(GM) O João mandou que-SBJV lavar-IMP-3SG os pratos mais rapidamente

'O João mandou que lavasse os pratos mais rapidamente'

b. O Yanis ${ }_{1}$ idhe na $\mathrm{cv}_{*_{1 / 2}}$ erxete.

O João viu-3SG vir-3SG

'O João viu que ele vinha'

Outra contraevidência para a obviação subjuntiva foi encontrada no infinitivo flexionado. No português, há dois contextos específicos que 
selecionam infinitivo flexionado e que exibem dois diferentes padrões de referencialidade: 1) os causativos/perceptivos e 2) os factivos / epistêmicos (cf. MEIRA, 2013). Nestes, há desencadeamento de referência livre; naqueles, de obviação, conforme ilustrado, respectivamente, em (14a) e (14b):

(14)

$$
\begin{aligned}
& \text { a. João e Maria }{ }_{1} \text { mandaram / } \text { viram } \text { eles }_{*_{1 / 2}} \text { saírem mais cedo } \\
& \text { b. João e Maria }{ }_{1} \text { lamentaram eles }{ }_{1 / 2} \text { sairem mais cedo }
\end{aligned}
$$

Todos esses dados constituem forte evidência de que obviação e controle não estão em distribuição complementar, visto que são exibidos em contextos variados. Adicionalmente, esses dados podem ser tomados como evidência também para a afirmação de que essas restrições parecem não dizer respeito ao tipo de complemento selecionado, mas ao tipo de predicado matriz que os seleciona, já que, de forma geral, os contextos de predicado causativo, de percepção física e volitivo são os únicos que exigem obviação nas línguas analisadas, o que torna evidente dois fatos sobre o desencadeamento desse fenômeno: (i) não se trata de uma competição entre formas finitas/não-finitas, já que não se tem infinitivo no grego, mas há obviação em outros contextos nessa língua, e a (ii) obviação não é uma propriedade restrita de contextos de morfologia de modo subjuntivo, pois é exibida também nas estruturas de predicados de percepção física, de complementação indicativa e de infinitivo flexionado selecionado por predicado causativo/perceptivo.

Neste artigo, tentaremos resolver os problemas apresentados, especialmente aqueles relacionados aos contextos obviativos, com base em análises de dados do português, fazendo comparação com sentenças do italiano e do grego moderno, que constituirão nossa fonte de investigação. Na próxima seção, apresentaremos os dados que tomaremos como base para a realização desta pesquisa.

\subsection{Padrões de referencialidade em complementação sentencial nas línguas}

Os padrões de referencialidade pronominal serão analisados em contextos de complementação sentencial com sujeitos, matriz e da encaixada, de $3^{\text {a }}$ pessoa. Nossos dados serão divididos em três grupos, conforme descrito a seguir, na Tabela 1 . 
TABELA 1 - Contextos de referencialidade em complementação sentencial

\begin{tabular}{c|l}
\hline a) & Predicados que exigem Obviação (Referência Disjunta) \\
\hline b) & Predicados que desencadeiam Controle (Correferência) \\
\hline c) & Predicados que exibem Referência Livre \\
\hline
\end{tabular}

Fonte: Meira, 2013, p. 48.

Os predicados de complementação subjuntiva analisados no português, italiano e grego foram os de verbos volitivos, causativos, factivos e psicológicos, respectivamente ilustrados em (15a), (15b), (15c) e (15d).

(15) a. O João ${ }_{1}$ quer que ele $*_{1 / 2}$ compre uma casa nova. (PB)

b. O Yanis parigile na plini ${ }_{*_{1 / 2}}$ ta piata pio grigora. (GM) O João mandou que-subj lavar-imper- $3^{\mathrm{a}} \mathrm{sg}$ os pratos mais rapidamente.

'João mandou que ele lavasse os pratos rapidamente.'

c. Giovanni ${ }_{1}$ si lamenta che $\mathrm{cv}_{*_{1 / 2}}$ compri una vecchia casa. (ITAL)

d. O João teme que $\mathrm{cv}_{1 / 2}$ reprove no exame. (PE)

No italiano, todos os predicados que selecionam morfologia de modo subjuntivo desencadeiam $\mathrm{RD}$, sendo o sujeito realizado ou nulo, conforme exemplo (15c), o que parece indicar que se trata de uma peculiaridade específica dessa língua. Por outro lado, o grego apresenta dois padrões de referencialidade em sentenças subjuntivas: as que desencadeiam RD nos predicados causativos, como ilustrado em (15b), e as que desencadeiam RL nos factivos, psicológicos e volitivos. ${ }^{3}$ No português foram observados dois padrões de referencialidade nos contextos de subjuntivo: (i) a RD, nos contextos de complementação a predicados volitivos e causativos, e (ii) aquele que licencia RL nos contextos de factivos e de verbos psicológicos. O grupo de predicados causativos e volitivos será tratado separadamente dos demais por exigirem OBV. A tabela a seguir sintetiza esse resultado.

\footnotetext{
${ }^{3}$ Remeto o leitor a Meira (2013) para uma visualização completa dos dados investigados.
} 
TABELA 2 - O padrão de referencialidade nos predicados subjuntivos no português, italiano e grego

\begin{tabular}{l|c|c|c}
\hline \multicolumn{1}{c|}{ Predicados } & Correferência & Referência Disjunta & RL \\
\hline Causativos & --- & PB/ITAL/GM & --- \\
\hline Volitivos & --- & PB/ITAL & GM \\
\hline Factivos/Psicológicos & --- & ITAL & PB/GM \\
\hline
\end{tabular}

Fonte: Meira, 2013, p. 53.

Esses dados demonstram que morfologia de modo subjuntivo não é uma condição sine qua non para se desencadear $\mathrm{RD}$, pelo menos não o é no português e no grego. O predicado causativo foi o único contexto em que a RD foi exibida em todas as línguas analisadas.

Com relação aos predicados indicativos, foram investigados quatro grupos: os predicados de percepção física, como no conjunto de sentenças em (16), de percepção mental, como em (17), epistêmicos, como em (18), e os declarativos, como ilustrado em (19).

(16) a. O João1 viu que ele*1/2 estava dormindo. (PB)

b. O João1 viu que cV*1/2 comprou o livro. (PE)

c. Giovanni1 ha visto che $\mathrm{cv}^{*} 1 / 2$ ha comprato il libro. (ITAL)

d. O Yanis 1 idhe $\mathrm{cv}^{*} 1 / 2$ na erxete. (GM)

O João viu-3sg comp vir-3sg.

'O João viu que ele vinha.'

(17) a. O João1 se lembrou que ele1/2 perdeu as chaves. (PB)

b. O João1 lembrou-se que cv1/2 perdeu as chaves. (PE)

c. Giovanni1 si è ricordato che cv1/2 ha perso le chiavi. (ITAL)

d. The Yanis1 thimithike oti cv1/2 aghorase tsighara. (GM)

O João lembrou-3sg que comprou-3sg cigarros.

'João se lembrou que comprou cigarros.' 
(18) a. O João1 acredita que ele1/2 comprará uma casa nova. (PB)

b. O João1 acredita que cv1/2 comprará uma casa nova. (PE)

c. Giovanni1 pensa che cv1/2 comprará una nuova casa. (ITAL)

d. Yanis 1 pistevi oti cv1/2 tha perasi stis eksetasis. (GM) João acredita-3sg que FUT passar-3sg nos exames.

'João acredita que ele passará nos exames. (ele ou outra pessoa).

(19) a. O João1 disse que ele $1 / 2$ comprará uma casa nova. (PB)

b. O João1 disse que cv1/2 comprará uma casa nova. (PE)

c. Giovanni1 ha detto che cv1/2 comprerà una nuova casa. (ITAL)

d. O Yanis1 lei oti cv1/2 tha fiji, (GM)

O João dizer-3sg que FUT ir-3sg

'João disse que ele partirá.'

Foi observado o mesmo padrão de referencialidade na complementação indicativa: (i) RD, quando a sentença encaixada é selecionada por predicados de percepção física, e (ii) RL, nos contextos de percepção mental, epistêmicos e declarativos. Esse fato merece investigação já que se trata de um caso excepcional no contexto de indicativo, por apresentar propriedade que seria a priori apenas peculiar à modalidade subjuntiva.

O perceptivo físico, apesar de ser semanticamente diferente do perceptivo mental, compartilha com este a mesma forma verbal, ao menos no português. Em (20), o verbo matriz ver possibilita duas acepções: (20a) a física e (20b) a mental.

(20)
a. João viu ele $_{*_{1 / 2}}$ dormindo
b. João ${ }_{1}$ viu que ele ${ }_{1 / 2}$ chegou atrasado

A primeira acepção diz respeito ao sentido físico da visão. João viu alguém (diferente de João) dormindo, percepção física (cf. FELSER, 1999). Essa acepção de ver desencadeia apenas OBV. A segunda acepção faz referência a um sentido mental, de perceber algo 
com base em alguma inferência, um relógio, por exemplo. Nesse caso, João percebeu que alguém ou ele mesmo chegou atrasado. Essa segunda acepção possibilita RL e, por ser uma fonte mental, relaciona-se mais a uma leitura epistêmica. Verbo perceptivo, quando seleciona infinitivo flexionado como complemento no $\mathrm{PB}$, pode apenas ser interpretado como de percepção física, admitindo apenas $\mathrm{OBV}^{4}$

Tomando como base os contextos de OBV apresentados, esse fenômeno, de forma geral, é desencadeado nos contextos de complementação sentencial independente do tipo de morfologia de modo (indicativo ou subjuntivo) e independente do contraste entre formas finitas/não-finitas. Por isso, investigaremos esses dados considerando os três tipos de contextos já expostos na Tabela 1 e, com base nisso, sintetizamos, na Tabela 3, uma descrição das línguas analisadas a respeito dos padrões de referencialidade.

${ }^{4}$ Agradeço ao parecerista anônimo pelas observações a respeito do fato de que o perceptivo físico pode, em alguns contextos, levar a uma leitura de referência livre, como (ib, ic e id), e essa mudança na referencialidade parece ser direcionada, segundo o parecerista, pelo tipo de predicado da encaixada, conforme se observa nos seguintes exemplos:
a. O João ${ }_{1}$ viu que ele ${ }_{*_{1} / 2}$ estava dormindo (PB)
b.João viu que ele $_{1 / 2}$ estava pegando fogo.
c. Pavarotti ${ }_{1}$ viu que ele $e_{1 / 2}$ estava com as suas calças pegando fogo.
d. João viu ele $_{1 / 2}$ correndo (Supondo o contexto de um espelho)

No entanto, mantenho minha opinião de que os contextos em (ia) e (id), tendo o sentido de percepção física, levam apenas a leitura de OBV, e de que os contextos em (ib) e (ic) possibilitam referência livre, já que o verbo da matriz tem o sentido de perceber, de sentir - portanto, de percepção mental. Na verdade, para o perceptivo fisico denotar essa leitura sugerida de correferência em (id), por exemplo, necessitaria de um pronome reflexivo, como em (ie), o que modifica o contexto analisado neste trabalho.

(i) e. João se viu (correndo) no espelho

Certamente, em alguns dialetos, diferentes leituras serão possíveis, mas a preferencial no contexto de perceptivo físico será a OBV. 
TABELA 3 - Tipos de padrões de referencialidade em complementação sentencial e seu contexto de ocorrência no Português, Italiano e Grego

\begin{tabular}{c|c|c}
\hline Contextos & Predicados Finitos & Não-finitos \\
\hline \multirow{2}{*}{ OBV } & $\begin{array}{c}\text { Causativos/Percepção física } \\
\text { (Todas as línguas) }\end{array}$ & $\begin{array}{c}\text { Causativos/Percepção Física } \\
\text { (Português) (Infinitivo flexionado) }\end{array}$ \\
\cline { 2 - 3 } & Volitivos (Português/italiano) & \\
\cline { 2 - 3 } & Factivos/Psicológicos (Italiano) & $\begin{array}{c}\text { Factivos (Português) } \\
\text { (Infinitivo flexionado) }\end{array}$ \\
\cline { 2 - 3 } & Factivos/Psicológicos (PE/PB/GM) & Volitivos (GM) \\
\cline { 2 - 3 } & $\begin{array}{c}\text { Epistêmicos/Declarativos/Percepção } \\
\text { Mental (Todas as línguas) }\end{array}$ & $\begin{array}{c}\text { Volitivo/Declarativo (PB) } \\
\text { (Infinitivo não-flexionado) }\end{array}$ \\
\hline \multirow{2}{*}{ Controle } & &
\end{tabular}

Fonte: Meira, 2013, p. 64.

A conclusão a que se pode chegar com base na Tabela 3 é a de que os contextos por excelência de ocorrência de OBV nas línguas analisadas são os predicados causativos e perceptivos físicos. $\mathrm{O}$ predicado volitivo apresenta variação, pois na complementação finita exibe RD e, na infinitiva, controle. Por outro lado, no GM, esse contexto exibe apenas RL, apesar da leitura padrão ser a de correferência. Na Tabela 4, apresentamos os contextos de RD obrigatória, de acordo com o que foi investigado até aqui.

TABELA 4 - Contextos de ocorrência de Obviação nas línguas analisadas

\begin{tabular}{c|c|c}
\hline Línguas & \multicolumn{2}{|c}{ Predicados } \\
\hline Grego Moderno & \multicolumn{2}{|c}{ Causativos - Perceptivos Físicos } \\
\hline Português & Causativos - Perceptivos Físicos & Volitivo \\
\hline Italiano & Causativos - Perceptivos Físicos & Predicados com morf. de SUBJ. \\
\hline
\end{tabular}

Fonte: Meira, 2013, p. 65.

Esses fatos deixam evidente que há algo em comum entre verbos de percepção física, causativos e volitivos que os levam a desencadear a OBV 
nas línguas. Mas qual seria essa propriedade? Na seção 4, apresentaremos alguns pontos em comum entre os predicados que exigem OBV, e são essas noções que nos guiarão no desenvolvimento deste trabalho. Antes disso, na próxima seção, será apresentada uma nota sobre alguns predicados que selecionam complementação indicativa e subjuntiva no grego, bem como os tipos de complementizadores que estruturam essas sentenças.

\subsection{Nota sobre os predicados de complementação indicativa e subjuntiva no grego}

A complementação sentencial a predicados de percepção física no grego com o complementizador $-n a$ pode ser constituída de duas maneiras diferentes: (i) sentença com um clítico, em que há subida do pronome para a oração matriz, como em (21a), e (ii) um predicado com Marcação Excepcional de Caso, do inglês Exceptional Case Marking (ECM), em que o sujeito da encaixada é marcado por Caso, pelo verbo matriz, como em (22b), ou seja, o iniciador da eventualidade encaixada será realizado como pronome clítico ou como DP. Em todos esses contextos, há RD obrigatória. Esses contextos se assemelham aos casos de predicado complexo admitidos também pelas línguas românicas.
a. O Yanis1 ton2 idhe $\mathrm{cv}^{*} 1 / 2$ na erxete.
O Joao ele/o viu-3SG PRT vir-3SG
'João o viu vindo'
b. O Yanis idhe tin alepu na erxete.
O João viu-3sg PRT a raposa-ACUS que vir-3sg
'O João viu que a raposa vinha'

Em contextos específicos, é também possível sentenças do tipo (22), como complemento de predicados de percepção física.
O Yanis 1 idhe $\mathrm{cv}^{*} 1 / 2$ na erxete.
O João viu-3sg comp vir-3sg
'O João viu que ele vinha'

No entanto, tanto o padrão de referencialidade quanto o sentido do verbo é alterado nos contextos de perceptivos com um complementizador -oti, como ilustrado em (23). 
(23)
O Yanis 1 idhe oti cv1/2 efaje kala.
O João viu-3sg PRT que-comp comeu-3sg bem
'João viu que ele comeu bem' (Ou João ou alguém comeu bem) mental:

No grego, há dois tipos de complementos a verbos de percepção

(i) complementos-oti (que): admitem apenas referência livre:

(24) O Yanis1 thimithike oti cv1/2 aghorase tsighara. (GM)

O João se lembrou-3sg que comprou-3sg cigarros

'O João se lembrou de que ele comprou cigarros'

(ii) complementos-na (que): desencadeiam como leitura padrão a correferência, mas a depender do contexto há leitura de RL.

(25) O Yanis1 thimithike na cv1/22 aghorasi tsighara. (GM)

O João se lembrou-3sg PRT que comprar-3sg cigarros

'João se lembrou de comprar cigarros'

No contexto de predicado epistêmico e de declarativos com -oti, admite-se apenas RL, conforme ilustrado respectivamente em (26a) e (26b/26b').

(26) a. O Yanis 1 pistevi oti cv1/2 tha perasi stis eksetasis.

O João acredita-3sg que PRT-FUT-passar-3sg no exame.

'João acredita que ele passará no exame. (ou ele ou outra pessoa)

b. Ta koritsia1 ipan oti cv1/2 tha pane sto sinema. (GM) As garotas disseram-3pl que PRT-FUT ir-3pl para o cinema. 'As garotas disseram que elas iriam para o cinema.' (ou as próprias garotas ou outras)

b'. O Yanis1 lei oti cv1/2 tha fiji.

O João diz-3sg que PRT-FUT partir-3sg

'O João diz que ele partirá.' (ou o próprio João ou alguma outra pessoa) 
No grego, há diferentes tipos de complementizadores. Por exemplo, predicados cujo complemento oracional é de subjuntivo terão complementizadores - na (que + subjuntivo). Oti, por outro lado, é um complementizador indicativo. Há ainda complementos com pu (que), como nos perceptivos físicos, factivos e psicológicos. Pu como relativizador ocorre em contextos de correferência, como em (27).

(27) Idha ton Petro pu efthase argha xthes vradi.

'Eu vi Pedro que chegou tarde noite passada.'

Por outro lado, complementos -pu, com um sujeito nulo, ocorrem nos predicados perceptivos físicos e OBV. ${ }^{5}$
a. Idha pu katharize.
'Eu1 vi que ele*1/2/ela estava limpando.'
b. *idha pu kathariza.
'Eu vi que eu estava limpando.'

Apesar das diferentes formas de complementizadores (-pu, -na, -oti) no grego, a RD obrigatória é exibida nos contextos de causativos e em construções de perceptivos físicos, o que parece sugerir que essa restrição é direcionada pelo tipo de predicado matriz.

\section{A relação entre os predicados causativos/volitivos e os de percepção física: as modalidades proposicional e de evento}

A categoria de modalidade tem sido classificada no mínimo em dois tipos nas línguas: a Epistêmica e a Deôntica (cf. LYONS, 1977; PALMER, 1986). Palmer (2001) redistribui as modalidades em deôntica e dinâmica, por um lado, e epistêmica e evidencial, por outro. Modalidade epistêmica pode ser definida como a categoria que descreve a opinião do falante diante de um índice proposicional, de uma situação (cf. PIETRANDREA, 2005). Por outro lado, a modalidade deôntica expressa obrigação e permissão, necessidade ou possibilidade de ações realizadas por um determinado agente (cf. HATAV, 1997, LYONS, 1977).

\footnotetext{
${ }^{5}$ Construções de perceptivo físico com - pu desencadeiam OBV.
} 
Predicados causativos e volitivos denotam o mesmo tipo de modalidade: a deôntica (cf. PALMER, 1986; HATAV, 1997; NORDSTROM, 2010; WYMAN, 2010). Causativos e volitivos estão inseridos dentro da chamada Modalidade Raiz (Root Modality), que expressa os sentidos de obrigação, permissão ou habilidade (cf. SWEETTSE, 1990; FRAWLEY, 1992; PIETRANDRE, 2005). Modalidade raiz inclui as modalidades deôntica e dinâmica: obrigação, permissão, habilidade, volição, i.e., agrupam as noções ligadas aos predicados causativos e volitivos (cf. LYONS, 1977; FRAWLE, 1992). Outra evidência de que volitivos também se relacionam semanticamente com a modalidade deôntica está no fato de eles indicarem mais uma ação possível do que a verdade de uma proposição (cf. PALMER, 1986).

Nosso foco nesta pesquisa são os predicados causativos, volitivos e perceptivos físicos, já que nesses contextos a RD é exigida obrigatoriamente entre sujeitos. Os dois primeiros predicados são classificados como de modalidade raiz. Os perceptivos físicos são tomados, pela literatura, como evidenciais (cf. GIVÓN, 1982 apud PIETRANDREA, 2005; WILLET, 1988; PALMER, 2001). Nesta pesquisa, argumentaremos que eles se distinguem dos perceptivos mentais por serem não epistêmicos, não proposicionais.

Palmer (2001) classifica os sistemas Epistêmico e Evidencial como tipos de modalidade Proposicional e os sistemas deôntico e dinâmico, como tipos principais da Modalidade de Evento. A relação entre eles pode ser interpretada da seguinte forma:

A modalidade epistêmica e a evidencial fazem referência à atitude do falante a um valor de verdade ou a um status factual da proposição (modalidade Proposicional). Por outro lado, as modalidades deôntica e dinâmica se referem a eventos que não são reais, eventos que não ocorreram, mas são meramente potenciais (modalidade de Evento). (PALMER, 2001, p. 08) ${ }^{6}$

\footnotetext{
6 “[...] epistemic modality and evidential modality are concerned with the speaker's attitude to the truth- value or factual status of the proposition (Propositional modality). By contrast, deontic and dynamic modality refer to events that are not actualized, events that have not taken place but are merely potential (Event modality)" (PALMER, 2001, p. 8)
} 
Eventos e proposições são noções que indicam as informações denotadas pelos predicados. Proposições se referem a pensamentos e a crenças (cf. PARSONS, 1990), indicam entidades mais abstratas, ligadas à mente do falante. Sentenças que expressam condições são também proposições. Proposição não pode ser tomada como uma entidade concreta, real, existe apenas na mente do falante. Eventos, por sua vez, são propriedades concretas e particulares, realizados em um tempo e espaço determinados, podendo ser mais genéricos ou mais especificos (cf. MONTAGUE, 1969; HIGGINBOTHAM, 2000). ${ }^{7}$

Como nosso foco é propor uma relação entre o tipo de modalidade denotada pelos predicados causativos, volitivos e perceptivos e mostrar a forma como isso se relaciona com a OBV, que é exigida por eles, apresentaremos nos parágrafos seguintes a modalidade denotada por esses predicados, que tipo de leitura (eventiva ou proposicional) eles denotam, a forma como essas noções semânticas são capturadas pela sintaxe e como a RD pode ser entendida nesse contexto.

Palmer (2001) classifica os evidenciais, que englobam os predicados perceptivos, como denotadores de modalidade proposicional. No entanto, não há um consenso na literatura a esse respeito. Butler (2004) toma infinitivos selecionados por predicados perceptivos físicos como denotadores de modalidade eventiva. Tomando proposição como uma noção que se refere a pensamentos, argumentamos que, como predicados perceptivos abarcam duas acepções - o perceptivo físico e o perceptivo mental -, a acepção denotada pelo perceptivo mental é mais ligada a impressões, a inferências causadas por determinada situação, tendendo a se relacionar mais a uma leitura proposicional, com um valor epistêmico. Por outro lado, a outra acepção dos perceptivos, a física, denota modalidade eventiva, relacionando-se com o que é mais concreto, não-epistêmico. Observe as sentenças em (29a) e (29b).

a. João viu Maria sair. (evento/percepção física da visão)

b. João viu que Maria gostava dele. (proposição/percepção mental, sentido de perceber)

\footnotetext{
${ }^{7}$ Para uma discussão mais aprofundada sobre a diferença entre proposição e evento, remetemos o leitor aos trabalhos de Montague (1969), Chisholm (1970), Pianesi e Varzi (2000), Higginbotham (2000), Parsons (1990), Asher (2000), dentre outros.
} 
A sentença em (29a) denota o que foi visto pelo sujeito, a ação realizada, o evento, ao passo que (29b) indica a impressão que o sujeito da sentença tem de determinada situação, denota uma leitura proposicional.

Butler (2004) observou que verbos infinitivos em inglês selecionados por predicados perceptivos físicos e epistêmicos possibilitam dois tipos de leituras. Os primeiros denotam uma leitura eventiva, enquanto que os verbos epistêmicos fazem referência a uma leitura proposicional. Sua argumentação se baseia nos dois tipos de infinitivos em inglês: o infinitivo nu e o precedido pela partícula to. $\mathrm{E}$ ele chega à conclusão de que verbos de percepção física são seguidos por um infinitivo nu, denotando uma leitura eventiva, ao passo que verbos epistêmicos selecionam infinitivo precedido por to e denotam uma leitura proposicional. Para ilustração, apresentamos o par de sentenças a seguir.

(30) a. I saw Mary sing. (Evento)

b. *I saw Mary to sing.

'Eu vi Maria cantar.'

(31) a. I believe Mary to have sung. (Proposição)

b. *I believe Mary sing.

'Eu acredito que Maria tenha cantado.'

Tomando como base essas pesquisas, assumimos proposição como objeto de crenças (cf. PARSON, 1990) e classificamos predicados epistêmicos e perceptivos mentais (cf. PALMER, 2001), como denotadores de proposições. Por outro lado, predicados perceptivos físicos serão tomados como denotadores de eventos, assim como os predicados de modalidade deôntica/dinâmica.

Modalidade deôntica expressa obrigação e permissão de ações realizadas por um determinado agente (cf. LYONS, 1977); causativos e volitivos denotam esse tipo de modalidade (cf. PALMER, 1986; NORDSTROM, 2010; WYMANN, 2010), possibilitando leitura eventiva. Predicados perceptivos físicos são classificados como Evidenciais (cf. HIGGINBOTHAM, 1983; PALMER, 2001) e denotam leitura não epistêmica (cf. FELSER, 1999). Os mentais, por sua vez, estão ligados aos epistêmicos. 
Predicados causativos, volitivos e perceptivos físicos em comum se caracterizam por propiciar leitura de RD obrigatória entre o pronome de $3^{\mathrm{a}}$ pessoa da oração complemento e o sujeito nominal de $3^{\mathrm{a}}$ pessoa da oração matriz. Esses predicados são denotadores de leitura eventiva, tem um caráter não epistêmico e propiciam leitura de OBV, em contraste com a leitura proposicional e a possibilidade de RL dos predicados epistêmicos. Isso é interessante na medida em que assumimos que uma leitura eventiva desencadeia, sintaticamente, uma estrutura diferente de um predicado que propicia leitura proposicional (cf. ROCHETTE, 1988; HORNSTEIN, MARTINS e NUNES, 2006).

Como a OBV é uma propriedade semântica de certos predicados, isso pode ser capturado na sintaxe pelo licenciamento de estruturas sintáticas distintas. De alguma forma, a OBV é admitida nos contextos de modalidade não epistêmica e nosso objetivo é demonstrar como isso é mostrado pela sintaxe.

No PB, os causativos e verbos de percepção física admitem OBV tanto na complementação finita quanto na infinitiva; por outro lado, os volitivos exigem esse fenômeno apenas na complementação finita. Duas razões podem explicar esses fatos: (i) a força causadora (deôntica) nos predicados causativos é maior do que nos volitivos, de acordo com uma perspectiva tipológica (ver PALMER, 1986; FELSER, 1999), uma vez que os volitivos expressam a modalidade dinâmica, o subtipo de modalidade deôntica e (ii ) a semântica do volitivo querer expressa pelo menos dois significados para denotar a ação realizada pelo sujeito: um ligado ao desejo de alguém para outra pessoa, vinculado a noções deônticas, de causalidade (ordem/pedido/desejo), que chamaremos de volitivo causativo, e outro ligado ao desejo de alguém para si mesmo, mais vinculado à noção de vontade. Nesse caso, assemelha-se mais a um auxiliar e não a um verbo principal e seleciona apenas o complemento infinitivo em português, que chamamos de volitivo padrão (default). Para resumir esses dados, veja a tabela 5.

TABELA 5 - Significados do predicado volitivo querer nas línguas românicas

\footnotetext{
Volitivo causativo = indica o desejo de alguém para outra pessoa realizar (OBV/não controle); Volitivo default = ligado ao desejo de alguém para si mesmo (Controle/correferência).
}

Fonte: Meira, 2013, p. 37. 
Em outras palavras, para explicar por que o verbo volitivo, nas línguas românicas, exibe duas estratégias para expressar referencialidade, OBV, em orações finitas e controle em frases infinitivas, adotamos, com base em Meira (2013), que, assim como o perceptivo (físico e mental), os verbos volitivos denotam dois significados, duas leituras, com diferentes propriedades semânticas e sintáticas, denominado por nós de volitivo causativo e volitivo padrão. A primeira, assim como o perceptivo físico e o causativo, exige OBV, licencia sujeito com caso nominativo na encaixada, seleciona $\mathrm{CP}$ em orações finitas e exibe dependência temporal entre TPs encaixado e matriz; o último não licencia sujeito visível na oração encaixada, requer leitura de controle, seleciona TP infinitivo, sem traço de Caso, e esse TP não é marcado por Tempo. Nesse caso, o predicado volitivo exibe dois tipos de acepções, com propriedades semânticas e configurações sintáticas diferentes, o que está ratificado na Tabela 6:

TABELA 6 - Propriedades do predicado volitivo

\begin{tabular}{c|c|c|c|c}
\hline Tipos de predicados & Padrão Ref. & $\begin{array}{c}\text { Estrutura } \\
\text { selecionada }\end{array}$ & $\begin{array}{c}\text { Sujeito } \\
\text { visível }\end{array}$ & Leitura \\
\hline Volitivo causativo & OBV & TP finito & $\sqrt{ }$ & Evento \\
\hline Volitivo padrão & Controle & TP não finito & --- & Evento \\
\hline
\end{tabular}

Fonte: Meira, 2013

No tzotzil, língua da família maia, o verbo volitivo $k$ 'an (querer) diferencia as duas acepções do volitivo por meio da inserção de um afixo verbal. $O$ volitivo padrão indica que o sujeito da matriz é idêntico referencialmente ao sujeito da encaixada, o que está ilustrado na sentença em (32a). Por outro lado, a acepção denotada pelo volitivo causativo é marcada pela construção ak'o + verbo subjuntivo, seguida ao verbo matriz. Nesse caso, o predicado matriz expressa a vontade de alguém que um outro faça alguma coisa; os sujeitos nesse contexto são disjuntos referencialmente, como mostram (32b) e (32c). 
a. Ta jk'an chkuch' vo.
'Quero beber água.'

b. Ali Xun e tzk'an ak'o xchan kastiya e. João 3-quer 3-aprender castelhano.

'João quer que ele (outra pessoa) aprenda castelhano (HAVILAND, 1981, p. 354)

c. Ta jk'an ak'o avuch' vo.

'Quero bebas água.' (HAVILAND, 1981, p. 353)

Só é possível a construção com $-a k^{\prime} o$ quando os sujeitos são diferentes. Construções com predicado volitivo $k$ 'an (querer) e a diferença semântica quando a construção com - ak'o é introduzida são evidências de que há diferenças morfológicas no predicado volitivo querer para denotar seus dois tipos de acepções, de leituras.

Os dados sugerem que restrições de referencialidade podem, de fato, estar ligadas a predicados não epistêmicos, e, nesse sentido, a OBV pode ser orientada pelo tipo de predicado matriz. A nossa hipótese é de que a RD obrigatória, do tipo investigado aqui, não é específica apenas a línguas românicas e ao grego, mas se estende a outras línguas, já que pode ser um fenômeno relacionado às noções semânticas do predicado matriz, especificamente dos causativos, perceptivos físicos e volitivos causativos. Como indica várias pesquisas, esses predicados são denotadores de leitura eventiva e sintaticamente desencadeiam uma estrutura diferente de um predicado que propicia leitura proposicional (cf. ROCHETTE, 1988; HORNSTEIN; MARTINS; NUNES, 2006).

Rochette $(1988)^{8}$ propõe uma Teoria da Complementação e difere sintaticamente complementos por meio de suas classes semânticas de predicados (Ação, Evento e Proposição), atribuindo-os, respectivamente, a realizações estruturais distintas, como VP, IP e CP. Em outras palavras, ela argumenta que esses tipos semânticos de complementos diferem estruturalmente e, nesse caso, complemento eventivo é uma projeção de INFL (casos de complementos infinitivos e subjuntivos), apresentando tempo dependente da oração matriz; complementos de ação são projeções

\footnotetext{
${ }^{8}$ Pesetsky $(1982,1992)$ também sugere relacionar um tipo semântico de predicado a determinada estrutura sintática.
} 
de VP, e complementos de proposição são projeções de CP. Raposo (1987), Pesetsky (1992), Cinque (2001) e Wurmbrand (2001) também mostram evidências de que complementos proposicionais são estruturas expandidas, CPs.

Rochette (1988) propõe uma análise para dar conta do efeito da OBV exibida nos complementos de verbos volitivos sob a luz da teoria de seleção semântica e sugere que volitivos sejam gerados como uma projeção da categoria INFL, subcategorizando IP, e o que é analisado como um elemento Case-spelling, elemento nucleando o $\mathrm{CP}$, numa posição entre o IP encaixado e o VP, matriz. Nesta pesquisa, tomaremos volitivo causativo como predicado que seleciona TP e leitura eventiva. A tabela a seguir resume algumas das propriedades listadas dos predicados de OBV.

TABELA 7 - Propriedades semânticas e configurações sintáticas de predicados de OBV

\begin{tabular}{c|c|c|c|c|c}
\hline Predicados & \multicolumn{3}{|c|}{ Propriedades } & Estrutura & $\begin{array}{c}\text { Sujeito } \\
\text { visível }\end{array}$ \\
\hline $\begin{array}{c}\text { Perceptivo Físico/ } \\
\text { causativo/volitivo } \\
\text { causativo }\end{array}$ & $\begin{array}{c}\text { Caráter não- } \\
\text { epistêmico }\end{array}$ & OBV & Evento & TP & $\sqrt{ }$ \\
\hline $\begin{array}{c}\text { Perceptivo mental/ } \\
\text { epistêmico }\end{array}$ & $\begin{array}{c}\text { Caráter } \\
\text { epistêmico }\end{array}$ & RL & Proposição & CP & $\sqrt{ }$ \\
\hline
\end{tabular}

Fonte: Meira, 2013.

Como vemos na Tabela 7, volitivo causativo é uma projeção de TP finito e não $\mathrm{CP}$, mas como explicar os complementos subjuntivos volitivos das línguas românicas que são introduzidos pelo complementizador que. Como dissemos, Rochette (1988) argumenta que o que é um 'casespelling element' que evita adjacência entre o verbo principal e o sujeito encaixado. Rochette afirma que o fato de que orações subjuntivas sejam projeções INFL explica algumas generalizações sintáticas subjuntivas, tais como: as restrições de tempo; o fato de orações subjuntivas não coocorrerem com wh-words. Outra evidência para analisar orações subjuntivas como IP é o fato de que complementos indicativos e subjuntivos se comportam diferentemente no que diz respeito à extração. A extração do 'tous' em francês é possível apenas quando há sentenças infinitivas e subjuntivas, sendo agramatical com complementos no 
indicativo. A extração de 'tous' é possível apenas em complementos VP e IP. Observe os seguintes exemplos:
a. Jean a
tous voulu les
lire

John has-3SG all wanted them PRO to read

'John has wanted to read them all'

b. Jean veut tous que Marie les lise

John wants-3SG all that Marie them reads-3SG-SBJV

'John wants Marie to read them all'

c. *Jean croit tous que Marie les lira

John believes-3SG all that Marie them will-read-3SG

'John believes that Marie will read them all' (ROCHETTE, 1998, p. 301)

Sugerimos ainda que predicados de OBV se caracterizam por serem de caráter modal, já que semanticamente impõem restrições aos seus complementos, como a referência disjunta entre os sujeitos matriz e da encaixada. Além disso, sintaticamente selecionam uma estrutra TP. Resumiremos na Tabela 8 os tipos de configurações de RD obrigatória.

TABELA 8 - Predicados de referência disjunta obrigatória

\begin{tabular}{c|c|c|c|c}
\hline Predicados & Estrutura & $\begin{array}{c}\text { Arg. ext. } \\
\text { encaixada }\end{array}$ & Padrão ref. & $\begin{array}{c}\text { Leitura } \\
\text { não-epistêmica/ } \\
\text { não proposicional/ } \\
\text { eventiva }\end{array}$ \\
\hline P\&C ECM & TP não-finito & Acusativo & OBV & $\sqrt{ }$ \\
\hline $\begin{array}{c}\text { P\&C-Infinitivo } \\
\text { flexionado }\end{array}$ & TP & NOM & OBV & $\sqrt{ }$ \\
\hline $\begin{array}{c}\text { Volitivo causativo/ } \\
\text { P\&C }\end{array}$ & TP & NOM & OBV & $\sqrt{ }$ \\
\hline
\end{tabular}

Fonte: Meira, 2013, p. 158.

Tomaremos a versão minimalista do conceito de subcategorização proposta por Adger (2004), aliada à proposta de s-seleção, para derivar as sentenças de OBV e para explicar seu efeito nas línguas, o que será exposto na próxima seção. 


\section{Uma proposta sintática para a RD em complementação sentencial}

Sintaticamente, predicados modais, ${ }^{9}$ tanto os de RD obrigatória quanto os de controle, terão as mesmas estruturas, complemento TP, diferenciando-se pela capacidade do T, nas estruturas de RD, de dispor de traço de caso. O TP das estruturas de controle, no português, será tomado como não finito, não dispondo de traço de caso e de tempo.

Predicados de OBV são tomados como marcados em relação aos predicados de controle, já que ambos são selecionados por predicados modais. Predicados epistêmicos são contextos neutros, por possibilitarem referência livre. Sintaticamente, esses predicados se distinguem dos predicados modais por selecionarem complemento $\mathrm{CP}$.

A OBV, em termos sintáticos, pode ser capturada da seguinte forma: o sujeito tem de ter seu Caso na encaixada checado, na posição de [Spec, TP], bem como todos seus outros traços. Em termos semânticos, o predicado matriz, da mesma forma que c-seleciona um complemento

\footnotetext{
${ }^{9}$ Diante das funções semânticas restritas que predicados de OBV desempenham na sentença, sugerimos que eles possam ser similares a verbos modais. Verbos modais constituem um conjunto pequeno de verbos que semanticamente expressam noções como obrigação, possibilidade, permissão, futuridade, dentre outras. Os exemplos tomados por nós para exemplificar essa classe de verbo, grifado em negrito, vêm do inglês.
}

(i) a. John must buy the house

'João deve comprar a casa'

b. John can buy the house.

'João pode comprar a casa'

Predicados de RD obrigatória também exibem noções semânticas como ordem, desejo, vontade e são capazes de exigir sujeito na encaixada referencialmente independente do sujeito matriz, o que é impossível para os outros predicados, como mostra o contraste entre (ii) e (iii) a seguir.

(ii) a. João pode comprar a casa

b. *João pode Pedro comprar a casa

(iii) João mandou Pedro comprar a casa

A sugestão de tomarmos predicados de $\mathrm{RD}$ obrigatória como verbos modais se deve ao fato de estes compartilharem restrições semânticas assim como aqueles. Nesse caso, uma das restrições semânticas impostas por volitivos, causativos e perceptivos físicos aos seus complementos é a RD. 
TP, também s-seleciona a referencialidade disjunta entre os DPs sujeitos, na posição de [Spec, TP], o que se torna possível pela c-seleção de TP. A OBV também poderia ser tomada como um traço transmitido pelo predicado matriz ao sujeito da encaixada, e isso é justificado pelo caráter modal dos predicados de RD obrigatória, por conter restrições semânticas. Nos contextos de ECM, esse traço [obv] poderia ser transmitido ao DP da encaixada no momento em que o núcleo $\mathrm{v}$ da oração superior checa o traço de caso [acus] do DP na posição de [Spec,TP] da encaixada. De qualquer forma, como o predicado matriz de contextos de OBV seleciona um TP na encaixada, não há violação do Princípio B da Teoria da Ligação, o que possibilita a OBV.

Os traços de Tempo (TP) podem ser apresentados como: traços- $\varphi$ , de [tempo] e o traço EPP, do inglês Extended Projection Principle (Princípio de Projeção Estendida); além disso, T pode ser associado a Caso, no sentido de conseguir valorá-lo. Os traços- $\varphi$ do verbo [+T] são não interpretáveis e, portanto, não são legíveis para os sistemas externos da interface, devendo ser valorados em uma relação de concordância. Chomsky diferencia dois tipos de $\mathrm{T}$, de acordo com sua relação com traços- $\varphi$ : (i) aquele com traços- $\varphi$ completos, T-completo e (ii) aquele com traços- $\varphi$ incompletos, T-defectivo.

Predicados de RD obrigatória selecionam TP finito, nos contextos de subjuntivo e indicativo, e TP não finito nos contextos de ECM. O TP finito é incompleto no sentido de que o T só conseguirá checar o traço de [caso] do DP depois que seus traços de [tempo] forem checados e valorados pelos traços de [tempo] da oração matriz, o que configura uma dependência temporal entre as orações. Essa será a análise que tomaremos para o TP finito incompleto. Por outro lado, o TP não finito não dispõe de traço de [caso], nem de traço de [tempo], como o TP do predicado ECM. Adotaremos a posição de que predicados ECM selecionam complemento TP não finito. Esse TP carregará traço EPP não interpretável, e o DP será concatenado na posição de [Spec,TP] da encaixada para checar esse traço. Como o TP é não finito, o traço de [caso] do DP não será checado e entrará em uma relação de checagem de caso com núcleo do vP matriz. Este valorará o caso do DP como [acus], o que configurará uma estrutura ECM. Essa será a análise que tomaremos para os predicados ECM P\&C do PB. 
Com relação aos complementos de infinitivo flexionado, nossa hipótese é a de que esses complementos são distintos estruturalmente a depender do tipo de predicado matriz que os seleciona, $\mathrm{P} \& \mathrm{C}$ ou factivos/epistêmicos. Estes permitem RL, e aqueles, RD obrigatória. A RL é desencadeada em complementos CP, por factivos, declarativos / epistêmicos (cf. RAPOSO, 1987; MADEIRA, 1994; SITARIDOU, 2002) e a OBV, em causativos e perceptivos, em complementos TP.

Assumiremos, com base na literatura já mencionada sobre infinitivo flexionado, que o TP do infinitivo flexionado é capaz de checar traço de [caso] do DP da encaixada, e o TP desses complementos terá traços-phi completos e será capaz de checar [caso]. Apesar de o infinitivo flexionado não ter marcas morfológicas de tempo, exibe marcas de número/pessoa.

No volitivo causativo, devido à dependência temporal da encaixada em relação à matriz, o núcleo $\mathrm{T}$, do complemento TP encaixado, só checará [caso] do DP, depois de ter seus traços de T valorados pelo $\mathrm{T}$ matriz, e o núcleo de TP encaixado tem traços de $\mathrm{T}$ não valorados nessas configurações. O complemento indicativo, subcategorizado por perceptivo físico, seleciona TP, e o núcleo T só checará Caso do DP depois de ter seus traços de $\mathrm{T}$ valorados pelo $\mathrm{T}$ matriz.

A derivação dos complementos dos predicados de OBV depende diretamente de requerimentos de Caso, já que há necessidade de dois sujeitos diferentes nas sentenças. Sabe-se que o núcleo T, de complemento infinitivo flexionado de perceptivo e causativo do português, pode atribuir Caso para o seu DP sujeito. Adicionalmente, verbo matriz ECM é capaz de atribuir caso para seu DP objeto, já que esses predicados c-selecionam um TP não finito, cujo núcleo T é incapaz de valorar caso. A tabela a seguir ilustra algumas propriedades dos predicados de OBV, de controle e de referência livre. 
TABELA 9 - Propriedades dos predicados em complementação sentencial e sua relação com a $\mathrm{RD}$

\begin{tabular}{|c|c|c|c|c|c|}
\hline Predicados & Traço [obv] & Leitura & Referência & Estrutura & Contruções \\
\hline $\begin{array}{c}\text { Volitivo padrão } \\
\text { Modais } \\
\text { Aspectuais }\end{array}$ & - traço [obv] & $\begin{array}{c}\text { Deôntica } \\
\text { (raiz) (volição/ } \\
\text { habilidade) }\end{array}$ & Controle & $\begin{array}{l}\text { TP (volitivo } \\
\text { padrão) } \\
--------- \\
\text { VP (Modais/ } \\
\text { aspectuais) }\end{array}$ & $\begin{array}{l}\text { - infinitivos } \\
\text { - orações - na }\end{array}$ \\
\hline $\begin{array}{c}\text { Epistêmico } \\
\text { Factivo } \\
\text { Perceptivo mental }\end{array}$ & Neutro & Epistêmica & $\mathrm{RL}$ & $\mathrm{CP}$ & $\begin{array}{c}\text { - Infinitivo } \\
\text { flexionado } \\
\text { - orações -ot } \\
\text { - indicativos } \\
\text { com que }\end{array}$ \\
\hline $\begin{array}{l}\text { Causativo } \\
\text { Volitivo causativo } \\
\text { Percepção física }\end{array}$ & + traço [obv] & $\begin{array}{c}\text { Eventiva/não- } \\
\text { epistêmica } \\
\text { Deôntico } \\
\text { (permissão) }\end{array}$ & $\begin{array}{c}\text { RD } \\
\text { (obviação) }\end{array}$ & $\mathrm{TP}$ & $\begin{array}{l}\text { - subjuntivos } \\
\text { com que } \\
\text { - infinitivo } \\
\text { flexionado } \\
\text { - orações -na } \\
\text { - infinitivo }\end{array}$ \\
\hline
\end{tabular}

Fonte: Meira, 2013, p. 193.

\subsection{Derivação de sentenças}

Para simplificar as derivações nos complementos analisados, serão descritas apenas as projeções TP, $\mathrm{vP}$ e VP, seguindo a hierarquia $\mathrm{T}-\mathrm{v}-\mathrm{V}$ e tomando como base a Teoria de Seleção Semântica (cf. CHOMSKY, 1986; ROCHETTER, 1988) e a versão minimalista de Subcategorização, proposta por Adger (2004). Por limitação de espaço, apresentaremos, neste artigo, apenas a derivação do volitivo causativo. As derivações para as demais sentenças estão disponíveis em Meira (2013) para onde remeto o leitor.

A derivação da sentença (34) pode ser aplicada aos contextos de predicados volitivos causativos com tempo encaixado dependente do da matriz. 
(34) João ${ }_{1}$ quer que ele $*_{*_{1 / 2}}$ compre a casa.

Numeração $=\{$ João [N, caso $], \mathrm{T}_{2}$ [pres, nom, $\left.u \mathrm{~N}^{*}\right], \mathrm{v}[u \mathrm{Infl}:]$, querer $[u \mathrm{~N}, u \mathrm{TP}]$, ele [N, caso $], \mathrm{T}_{1}\left[u \mathrm{~N}^{*}, u\right.$ Infl: , nom, $\left.i \mathrm{TP}\right], \mathrm{v}[u \mathrm{Infl}:]$, comprar $[u \mathrm{~N}, \mathrm{~V}]$ a casa $[\mathrm{N}]\}$

$\mathbf{1}^{0}$ passo: A derivação tem início com a relação de checagem no VP. Comprar é concatenado com o DP a casa e checa seu traço $[u \mathrm{~N}]$, como mostra a configuração em (1).

(1) $\operatorname{VP}[\operatorname{comprar}[\mathfrak{u N}]$ a casa $[\mathrm{N}]]$

$2^{\circ}$ e $3^{\circ}$ passos: v é selecionado da Numeração e concatenado com a estrutura (1). Nessa etapa, o verbo se move para v e o DP ele entra na derivação, é concatenado na posição de $[\mathrm{Spec}, \mathrm{vP}]$ e recebe seu traço temático.

(2)

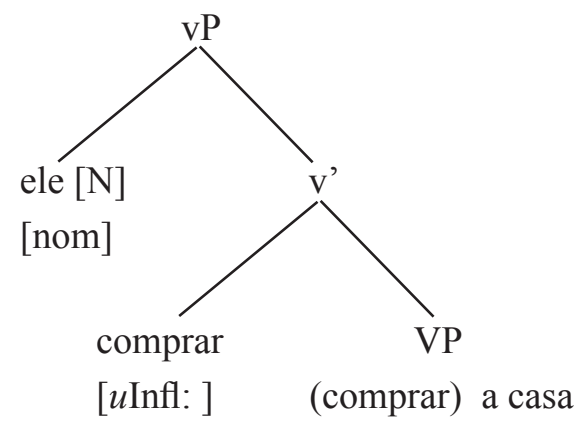

$4^{0}$ passo: $T_{1}$ é selecionado e concatenado com a configuração em (2). Como é um $\mathrm{T}$ dependente do $\mathrm{T}$ matriz, não pode valorar os traços de tempo de v, nem checar [caso] do DP, na posição de [Spec,vP], que sobe para a posição de $[\mathrm{Spec}, \mathrm{TP}]$ para checar o traço $\left[u \mathrm{~N}^{*}\right]$, que é o EPP em $\mathrm{T}$. 


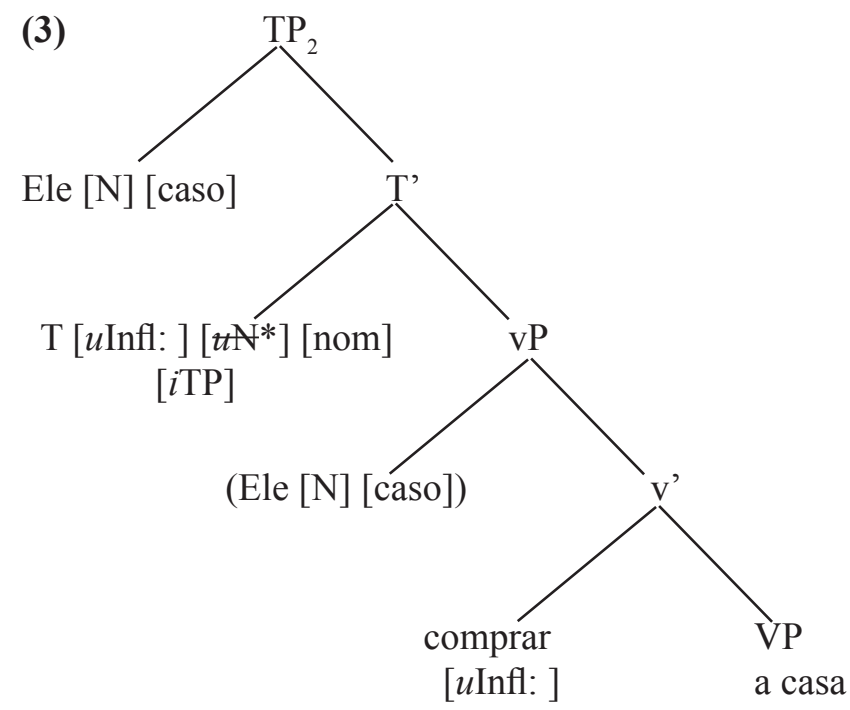

$5^{\circ}$ passo: Querer é selecionado da Numeração e concatenado com a estrutura em (3), checando seu traço [uTP]. Obviação, para Rochette (1988), pode ser explicada pelo Princípio B da Teoria da Ligação, quando complementos subjuntivos a verbos emotivos são analisados como IP, assumindo, assim, que o 'que' não bloqueia regência dos sujeitos encaixado e matriz. Se o regente do sujeito encaixado é o verbo matriz, então o Domínio de Ligação é a oração matriz.

(4)

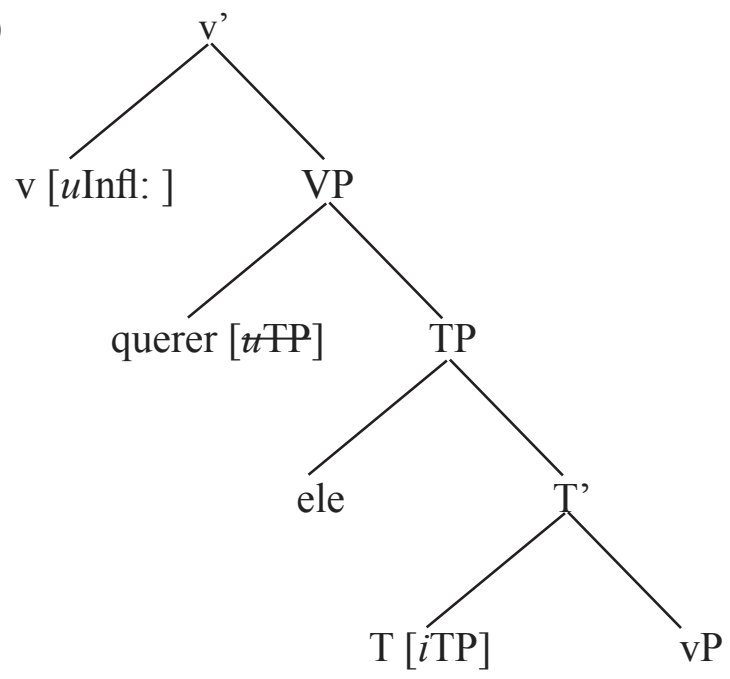


$6^{\circ}$ passo: O DP, João, é concatenado na posição de [Spec,vP]. $\mathrm{T}_{2}$ entra na derivação e é concatenado com a estrutura em (4). $\mathrm{O}$ núcleo $\mathrm{T}_{2}$ concorda com o $\mathrm{T}_{1}$ e valora seu traço de tempo como [+ presente], como o da matriz e $\mathrm{T}_{1}$ valora o traço de caso [nom] de ele e valora os traços de tempo do $\mathrm{v}$ encaixado. $\mathrm{O}$ núcleo de $\mathrm{TP}_{2}$ valora o traço de caso [nom] do DP João, que sobe para a posição de $\left[\mathrm{Spec}, \mathrm{TP}_{2}\right]$ para checar o traço $\left[u \mathrm{~N}^{*}\right]$ em $\mathrm{T}_{2}$. Adicionalmente, $\mathrm{T}$ e $\mathrm{v}$ da matriz entram em concordância, $\mathrm{T}$ checa e valora os traços flexionais em v, como [presente]. Sendo traços de T forte, o verbo na posição de núcleo de vP sobe para a posição de núcleo de TP. No português, francês e italiano, quando traços flexionais (Infl) em v são valorados como tempo, eles são sempre fortes, subindo para a posição de T, em TP.

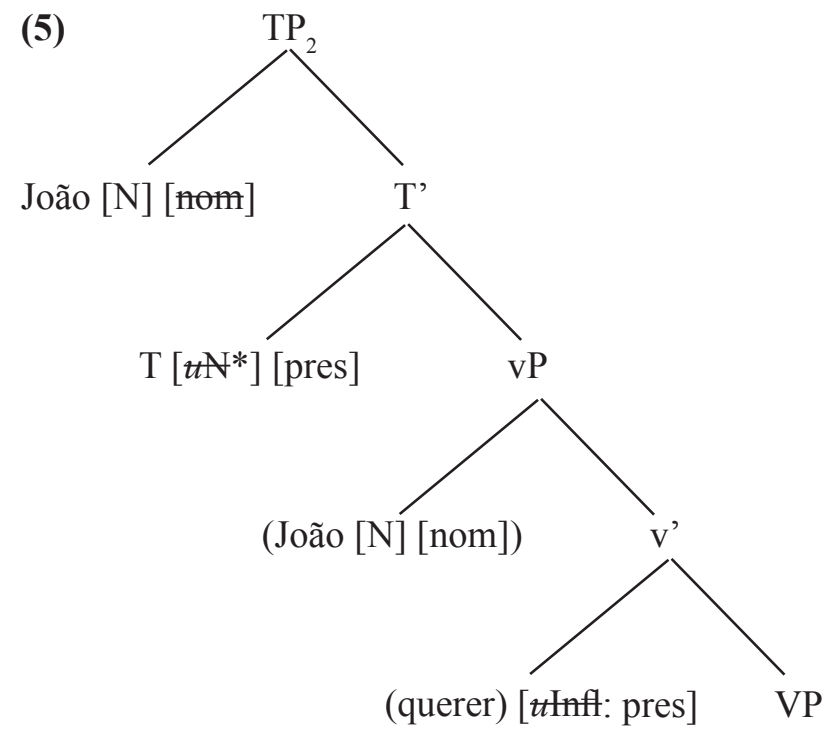

Com relação aos predicados que exigem OBV no grego e sobre o volitivo nessa língua, que possibilita RL, diacronicamente, o grego perdeu tanto seu infinitivo, quanto marcas de subjuntivo. Este é marcado pela partícula -na. Construções com -na subjuntivo abarcam no grego tanto os contextos que eram antes de infinitivo, quanto contextos de subjuntivo. Pesquisadores sobre línguas da área balcânica têm tratado tradicionalmente a questão da subcategorização de predicados subjuntivos de duas formas: (i) a partícula - na tem sido tomada como 
um complementizador que assume diferentes formas dependendo do complemento verbal, se indicativo -oti, se subjuntivo - na (cf. SAN MARTIN, 2007) ou (ii) assume-se que a partícula -na é um marcador subjuntivo (cf. TERZI, 1992; RIVERO, 1988).

A primeira impressão é a de que sentenças volitivas e causativas são idênticas estruturalmente, já que ambas têm seu complemento encabeçado pela partícula $-n a$, como em (35a) do volitivo e (35b), causativa. Uma diferença entre elas é que o volitivo permite RL, e o causativo, OBV.

$$
\begin{aligned}
& \text { a. O Yanis }{ }_{1} \text { theli } \quad \text { na } \\
& \text { O Joajo quer } \text { subj }_{1 / 2} \text { (SITARIDOU, 2007, p. 201) } \\
& \text { partir }
\end{aligned}
$$

b. O Yanis ${ }_{1}$ parigile na plini ${ }_{*_{1 / 2}}$ ta piata pio grigora O João mandou PRT-subj lavar- $3^{\mathrm{a}} \mathrm{sg}$ os pratos mais rapidamente

A nossa hipótese é a de que complementos que desencadeiem $\mathrm{RL}$, como em (35a), sejam tomados como $\mathrm{CP}$, e complementos que exijam OBV sejam um TP, como (35b). Trataremos o volitivo grego como selecionador de estrutura CP (cf. BALLESTA, 1993), já que o-na é tomado como um complementizador. Isso confirma a nossa hipótese, pois o volitivo permite RL. A alternativa que temos para explicar essa diferença do volitivo grego com o volitivo de outras línguas parte de uma perspectiva histórica. Provavelmente, com a perda do infinitivo no grego e com a perda das marcas flexionais do subjuntivo no verbo, passando para um $\mathrm{C}$ subjuntivo, e com o surgimento de um comp subjuntivo -na (cf. SAN MARTIN, 2007), o volitivo tenha perdido sua função modal e, com isso, suas restrições semânticas (controle obrigatório ou RD obrigatória) e passou a permitir a RL, funcionando, assim, como um verbo lexical. Isso seria uma alternativa para explicar a não predominância nas sentenças do grego de um volitivo padrão, com controle, ou de um volitivo causativo, com OBV. O volitivo grego permite a RL, o que configura que não há restrição semântica imposta por esse predicado. Essa ideia dá conta do volitivo nessa língua, com seu complemento CP, exibindo RL, confirmando a nossa proposta.

Ballesta (1993) observa que predicados causativos no grego não podem ser classificados como similares estruturalmente a volitivos e sugere que as restrições e algumas peculiaridades daqueles verbos 
sejam consequência de fatores semânticos. Com relação aos predicados perceptivos físicos, funcionam como verbos ECM.

\section{Considerações finais}

Nesse artigo, tivemos como objetivo: (i) mostrar que finitude e a relação que a literatura faz entre controle/infinitivo e obviação/subjuntivo não é suficiente para explicar as estruturas de controle e obviação nas línguas e (ii) mostrar que a obviação é uma restrição semântica imposta por um grupo de predicado matriz aos seus complementos, sendo isso capturado sintaticamente. Diante disso, a obviação exibida em complementação sentencial não é um fenômeno restrito a línguas românicas ou a línguas que exibam a distinção finito / não finito, mas é uma restrição semântica imposta por predicados de obviação (não epistêmicos) a seus complementos e, devido a isso, essa restrição semântica será exibida por línguas que dispõem desses contextos em complementação sentencial.

\section{Referências}

ADGER, David.Core Syntax. A Minimalist Approach. Oxford. University Press, 2004.

BORER, Hagit. Anaphoric AGR. In: JAEGGLI, Osvaldo; SAFIR, Kenneth. The Null Subject Parameter. Dordrecht; Boston; London: Kluwer Academic Publishers, 1989.

BOUCHARD, D. The Avoid Pronoun Principle and the Elsewhere Principle. In: SELLS, P.; JONES, C. (Ed.). Proceedings of ALNE 13/ NELS 13. Amherst: GLSA. 1984. p. 29-36.

CHIERCHIA, G. Anaphora and attitudes «De Se». In: BARTSCH, R.; van BENTHEM, J. F. A. K; BOAS, van Emde (Ed.). Semantics and Contextual Expressions. Kluwer; Reidel: Foris Publications, 1989.

CHOMSKY, Noam. Lectures on Government and Binding. Dordrecht: Foris, 1981.

COSTANTINI, Francesco. Subjunctive Obviation: an Interface Perspective. 2005. 183f. Tese (Doutorado) - Faculdade de Línguas, Università Ca' Foscari, Veneza, 2005. 
FARKAS, Donka. On Obviation. In: SAG, Ivan; SZABOLCSI, Anna. Lexical Matters. Center for the Study of Language and Information. Stanford University: CSLI, 1992.

FELSER, Claudia. Verbal complement Clauses. A minimalist study of direct perception constructions. John Benjamins Publishing Company, 1999.

FERREIRA, M. Argumentos Nulos em Português Brasileiro. 2000. 113f. Dissertação (Mestrado em Linguistica) - Instituto de Estudos da Linguagem, Unicamp, Campinas, 2000.

HIGGINBOTHAM, James. The logic of perceptual reports: an extensional alternative to situation semantics. Journal of Philosophy, Columbia University, n. 80, p.100-127, 1983.

KEMPCHINSKY, P. Mood Phrase, Case Checking and Obviation. In: SCHWEGLER, A; TRANEL, B.; URIBE-ETXEBARRIA, M. (Org.). Romance Linguistics: Theoretical Perspectives. Amsterdam; Philadelphia: John Benjamins, 1998. p. 143-154. Doi: https://doi. org/10.1075/cilt.160.12kem

KRAPOVA, I. Subjunctives in Bulgarian and Modern Greek. In: RIVERO, Maria Luisa; RALLI, Angela. Comparative Syntax of Balkan Languages. Oxford: University Press, 2001.

LYONS, H. Case and expletives. Linguistic Inquiry, MIT Press, n. 23, p. 381-405, 1977.

MEIRA, Vivian. A obviação/referência disjunta em complementação sentencial: Uma proposta sintático-semântica. 2013. 229f. Tese (Doutorado em Linguística) - Instituto de Estudos da Linguagem, Universidade Estadual de Campinas. Campinas, 2013.

NORDSTROM, J. Modality and subordinators. Amsterdam: John Benjamins, 2010. Doi: https://doi.org/10.1075/slcs.116

PALMER, F. Mood and Modality. 2. ed. Cambridage: Cambridge University Press, 2001.

PALMER, F. Mood and Modality. Cambridge University Press, 1986. 
RAPOSO, Eduardo. Romance Infinitival clauses and Case Theory. In: NEIDLE, C.; NÚÑEZ-CEDEÑO, R.(Ed.). Studies in Romance Languages. Dordrect: Foris, 1987. Doi: https://doi.org/10.1515/9783110846300 RAPOSO, Eduardo. Some asymmetries in the Binding Theory in Romance. The Linguistic Review, De Gruyter, n. 5, p. 75-110, 1985.

ROCHETTE, Anne. Semantic and Syntactic Aspects of Romance Sentential Complementation. 1988. Tese (Doutorado) - Massachusetts Institute of Tecnology, 1988.

SAN MARTIN, Itziar. Beyond the Infinitive vs. Subjunctive Rivalry: surviving changes in Mood. In: EGUREN, Luis; FERNANDEZSORIANO, O. (Org). Coreference, Modality and Focus. Studies on the syntax-semantics interface. Amsterdam; Philadelphia: John Benjamins Publishing Company, 2007. 
